Discussion Paper No. 05-32

\title{
Energy Biased Technical Change A CGE Analysis
}

Vincent M. Otto, Andreas Löschel and Rob Dellink

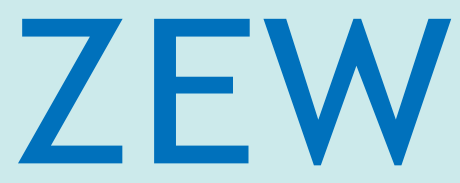

Zentrum für Europäische Wirtschaftsforschung $\mathrm{GmbH}$

Centre for European

Economic Research 
Discussion Paper No. 05-32

\title{
Energy Biased Technical Change A CGE Analysis
}

\author{
Vincent M. Otto, Andreas Löschel and Rob Dellink
}

Download this ZEW Discussion Paper from our ftp server:

\section{ftp://ftp.zew.de/pub/zew-docs/dp/dp0532.pdf}

Die Discussion Papers dienen einer möglichst schnellen Verbreitung von neueren Forschungsarbeiten des ZEW. Die Beiträge liegen in alleiniger Verantwortung der Autoren und stellen nicht notwendigerweise die Meinung des ZEW dar.

Discussion Papers are intended to make results of ZEW research promptly available to other economists in order to encourage discussion and suggestions for revisions. The authors are solely responsible for the contents which do not necessarily represent the opinion of the ZEW. 


\section{Nontechnical summary}

This paper studies energy bias in technical change (TC). We develop a computable general equilibrium model that builds on endogenous growth models. More specifically, we incorporate Acemoglu's (2002) theoretical modeling framework and specify TC in four ways. First, R\&D firms decide whether or not to enter markets for knowledge capital (innovation). Firms can choose between markets for knowledge capital appropriate for production of energy-intensive goods or non-energy intensive goods - both characterized by monopolistic competition. Second, producers decide upon adoption of these two types of knowledge capital (diffusion). Third, there is feedback between these phases of TC. Learning-by-doing, learning-by-using, and network externalities, among others, underlie such feedback. Finally, knowledge stocks built up in the specific intermediate sectors spill over to the respective production sectors as well. Thus, the model explicitly captures links between energy, the rate and direction of TC, and the economy. We subsequently derive the equilibrium determinants of biased TC and illustrate the model with simulations, in which we reduce the number of allocated emission rights associated to energy use. We find that feedback in TC, substitution possibilities between final goods, and general equilibrium effects are key determinants of the equilibrium bias in TC. We confirm Acemoglu's finding that TC is biased toward the relatively abundant good (non-energy intensive) if the final goods are gross substitutes and that TC is biased toward the relatively scarce good (energy intensive) if the final goods are gross complements. However, in our CGE setting we find that the usual substitution effect reinforces the market size effect causing an equilibrium bias in TC toward the non-energy intensive good even when both goods are gross complements. If, and only if, the substitution effect is absent is the price effect strong enough to outweigh the market-size effect. The equilibrium bias toward the non-energy intensive good is more pronounced if positive feedback occurs in TC. If both goods are very close substitutes, or if the positive feedback effect is strong, or both, the model can yield a corner solution in which only knowledge capital is developed and manufactured that is appropriate for production of the non-energy intensive good. All this is of public concern. The more substitution possibilities exist between the final goods, the less the environmental policy reduces welfare and the rate of TC. If the substitution elasticity is sufficiently large, or the positive feedback is strong enough, or both, environmental policy might even raise the rate of TC in the non-energy intensive sector relative to the reference. Regarding the positive feedback in TC, a case for policy intervention arises as social returns to R\&D diverge from the private returns since such feedback is external to agents' decision-making. If feedback effects differ between sectors these intervention should be directed towards specific sectors. 


\title{
Energy Biased Technical Change: A CGE Analysis
}

\author{
Vincent M. Otto ${ }^{\text {a, b }}$, Andreas Löschel ${ }^{\mathrm{c}}$, and Rob Dellink ${ }^{\mathrm{a}}$
}

\begin{abstract}
This paper studies energy bias in technical change. For this purpose, we develop a computable general equilibrium model that builds on endogenous growth models. The model explicitly captures links between energy, the rate and direction of technical change, and the economy. We derive the equilibrium determinants of biased technical change and show the importance of feedback in technical change, substitution possibilities between final goods, and generalequilibrium effects for the equilibrium bias. If the feedback effect is strong, or the substitution elasticity large, or both, our model tends to a corner solution in which only technologies are developed that are appropriate for production of non-energy intensive goods.
\end{abstract}

JEL classification: O32, O33, O38, H23, D58

Keywords: computable general-equilibrium models, endogenous technical change, energy, environment

\footnotetext{
* This paper was written while Vincent Otto was Marie Curie fellow at ZEW. Otto gratefully acknowledges TNOMEP and the EC Marie Curie program for their financial support. Löschel acknowledges financial support from the German Federal Ministry of Economics and Labour under the project "Innovation and modern energy technology" of the "Forum for Energy Models and Energy-Economic Systems Analysis". We would like to thank Christoph Böhringer, Ekko van Ierland, Timo Kuosmanen, Tinus Pulles, Toon van Harmelen, Reyer Gerlagh, Ian Sue Wing and colleagues at the ZEW and MIT for helpful comments. The usual disclaimer applies.

${ }^{\text {a }}$ Environmental Economics and Natural Resources group, Wageningen University, Wageningen, The Netherlands

${ }^{\mathrm{b}}$ Corresponding author, telephone: +31 317 484255, fax: +31317484933, email: vincent.otto@wur.nl

${ }^{\mathrm{c}}$ Centre for European Economic Research (ZEW), Mannheim, Germany
} 


\section{Introduction}

The last two decades saw the emergence of theoretical growth models in which technical change (TC) was no longer specified exogenously, but endogenously. Well-known examples of such models are the product-variety model of Romer (1990) and the quality-ladder model of Aghion and Howitt (1992). Yet, for long attention was mainly focused on how to sustain positive growth and therefore on the rate of TC. Recently, the bias in TC is receiving further attention since Acemoglu (2002) presented a modeling framework in which the bias in TC is also specified endogenously. Biased TC is of public concern, as regulatory measures affect different technologies differently. Depending on the economic characteristics of technologies, regulatory measures can therefore lead to different societal impacts and welfare costs. Thus, induced TC is not as straightforward as it may appear. In addition, if technologies have different external effects, or if markets for technologies are imperfectly competitive, or both, a case for directed policy intervention arises.

Beside these theoretical contributions, several recent modeling studies show the importance of an endogenous specification of the rate of TC for climate-change analysis. Studies by Nordhaus (1999), Goulder and Schneider (1999), Goulder and Mathai (2000), Buonanno et al. (2003), Popp (2003), Gerlagh and van der Zwaan (2003), Gerlagh and Lise (2003), and Sue Wing (2003) all analyze effects of endogenous TC on the design, timing, or attractiveness of climate-change policies. Nordhaus specifies R\&D expenditures in his R\&DICE model creating an aggregate knowledge-stock, which has a lowering effect on the emission-output ratio. He rudimentarily accounts for spillovers by assuming that the social and private returns on R\&D diverge. Popp follows Nordhaus except that R\&D occurs in an energy-R\&D sector in his ENTICE model, where energy R\&D is subject to decreasing returns to scale and is assumed to partly crowd out other expenditures. His aggregate stock of knowledge enters the energy-production function as a substitutable input. Buonanno et al. specify a world-wide stock of knowledge in their ETC-RICE model that enters countries' production functions and has a negative effect on countries' emission-output ratios. Sue Wing specifies an aggregate knowledge-stock entering sector's production functions as a substitutable input. Goulder and Schneider incorporate sector-specific expenditures on R\&D that form sector-specific stocks of knowledge capital, where these stocks spill over to representative firms in the specific sector and where the resources available for all R\&D expenditures are in fixed supply. Goulder and Mathai specify an aggregate knowledge-stock having a negative effect on abatement costs. Moreover, they incorporate a learning curve in the abatement sector. Gerlagh and Lise specify in their DEMETER-2 model an aggregate energy R\&D sector building a stock of knowledge that (i) enters production functions of two types of energy as a substitutable input, (ii) spills over to these energy production functions, and (iii) leads to learning-by-researching. In addition, experience gained in the production of these two types of energy builds a second 
stock of knowledge that enters energy production functions as a substitutable input as well. Learning rates, however, are constant and the same for both energy technologies. Finally, they specify S-shaped diffusion curves for both energy technologies. Though these studies recognize the importance of biased TC for climate change analysis, however, they do not capture this issue explicitly, or not at all, in their models. Goulder and Schneider (1999), for example, capture biased TC when showing the importance of opportunity costs of induced technical change although it remains unclear what exactly the determinants of this bias are in their framework. Jakeman et al. (2004) does capture biased TC explicitly. Yet, this bias depends only on input prices while the aggregate rate of TC remains autonomous in their specification.

Given the importance of biased TC and the apparent gap in applied modeling studies, we proceed by deriving the determinants of equilibrium bias in TC. Subsequently, we study how, and to what extent, environmental policy has an effect on the rate, but especially the bias of TC. For this purpose, we develop a computable general equilibrium (CGE) model that captures connections between energy use, the rate and direction of TC, and the economy. ${ }^{\text {a }} \mathrm{We}$ incorporate Acemoglu's (2002) theoretical modeling framework and specify TC in four ways. First, R\&D firms decide whether or not to enter markets for knowledge capital (innovation). Firms can choose between markets for knowledge capital appropriate for production of energy-intensive goods or non-energy intensive goods. Both markets are characterized by monopolistic competition. Second, producers decide upon adoption of these two types of knowledge capital (diffusion). Third, there is feedback between these phases of TC. Learningby-doing, learning-by-using, and network externalities, among others, underlie such feedback. Finally, knowledge stocks built up in the specific intermediate sectors spill over to the respective production sectors as well.

The novel contribution of our study is two-fold. In an applied framework, we show the importance of (i) feedback in TC and (ii) general equilibrium effects for the equilibrium bias in TC, in addition to Acemoglu's partial equilibrium effects. The rest of the paper is organized as follows. Section 2 presents the model in detail. In Section 3 we discuss results that we obtain with policy simulations. Section 4 concludes.

\section{Model description}

Several economic agents interact over time by demanding and supplying commodities on markets. These agents are producers of final goods in production sector $i$, an intermediate sector manufacturing knowledge capital $i$ for the respective production sectors, and a representative consumer. Final good $X$ has a relatively high energy content whereas good $Y$ has a relatively low energy content. Each agent is assumed to behave rationally and to have

\footnotetext{
${ }^{a}$ Note that environmental quality does not affect the economy.
} 
perfect foresight. The markets for both final goods and for production factors labor and physical capital are perfectly competitive whereas markets for both types of knowledge capital are characterized by monopolistic competition based on the Chamberlinian largegroup assumption - firms have a monopoly over their own variety of knowledge capital although there are many close substitutes available. Monopolistic competition and external effects support nonconvexities in the production possibility frontiers of the final goods, which are due to a nonrival knowledge input. Nonrival inputs also cause nonconvexities in the innovation possibility frontier that are supported by external effects only.

Each agent solves its own optimization problem and when all markets clear simultaneously, the allocation- and price vectors constitute a competitive equilibrium. Economic growth is determined by the growth rates of the stocks of physical- and knowledge capital, and of the labor supply. Growth of labor supply is exogenous and constant over time. Growth rates of both capital stocks are endogenous and reflect investment decisions of the representative consumer. The economy achieves steady-state growth over time with the stocks of physicaland knowledge capital growing at the same rate as the labor supply. We present a detailed structure of the model in the Appendix, and will discuss the main model elements below.

\section{Representative consumer}

The representative consumer maximizes her intertemporal utility function subject to the lifetime budget constraint. The intertemporal utility function is a nested constant-elasticity-ofsubstitution (CES) aggregate of the discounted sum of consumption of goods $X$ and $Y$ versus leisure time over the time horizon (see equations A.7 and A.8 in the appendix). Unlike in integrated assessment models, environmental quality does not enter the utility function, implying full separability between consumption and environmental policy.

\section{Producers of final goods}

Production of the final good is characterized by a production possibility frontier, which is a Cobb-Douglas function of physical capital $\left(K_{i, t}\right)$, labor $\left(L_{i, t}\right)$, emission rights $\left(E_{i, t}\right)$ associated with energy use, and a Dixit-Stiglitz aggregate of available varieties of knowledge capital $\left(K C_{i, t}\right)$, i.e. the "Romer" production function. We assume knowledge capital $i$ to be 'appropriate' for particular combinations of inputs only, i.e. the production function of final good $i$ ( $c f$. Basu and Weil, 1998). Hence, one type of knowledge capital cannot be used in the production of the other final good. Vintages of these varieties are differentiated but equally preferred. Value shares are determined by base-year demands. This is not the complete picture, however, because knowledge generated by intermediate sector $i$ 's aggregate R\&D activities spill over, enhancing production possibilities: 


$$
Q_{i, t}=N S_{i, t}^{\gamma_{i}} \cdot K_{i, t}^{\alpha_{i}^{Q}} \cdot L_{i, t}^{\beta_{i}^{Q}} \cdot E_{i, t}^{\chi_{i}} \cdot K C_{i, t}^{1-\alpha_{i}^{Q}-\beta_{i}^{Q}-\chi_{i}} \quad(t=1, \ldots, T),(i=X, Y)
$$

where $\gamma_{i}$ reflects the spillovers from the stock of blueprints $\left(N S_{i, t}\right)$. Together with adoption of knowledge capital, these spillovers drive productivity growth in the production sectors. Firms in production sector $i$ maximize their profits over time subject to their productionpossibility frontier. Homogeneity-of-degree-one, in addition to perfect competition, guarantees zero profits. Market clearing implies that the relative price of the goods, $P Q_{X, t} / P Q_{Y, t}$, has to satisfy the product-mix efficiency constraint:

$$
\frac{P Q_{Y, t}}{P Q_{X, t}}=\left(\frac{\theta_{X}^{C}}{1-\theta_{X}^{C}} \cdot \frac{Q_{Y, t}}{Q_{X, t}}\right)^{\frac{-1}{\sigma_{W}^{\text {gest }}}} \quad(t=1, . ., T)
$$

where $\theta_{X}^{C}$ is the share of good $X$ in total consumption and $\sigma_{W}^{\text {nest }}$ is the substitution elasticity between the final goods in instantaneous utility. An increase in the relative supply of a good lowers its relative price, satisfying the law of demand. The change in relative price is smaller the more substitutable the goods are.

\section{Manufacturers of knowledge capital}

Two intermediate sectors, $Z_{X}$ and $Z_{Y}$, manufacture the knowledge capital appropriate for production of goods $X$ and $Y$. Knowledge capital is assumed to be excludable but nonrival: its owner can prevent others from using it by deciding not to sell or rent but use by one firm does not preclude use by another. Software is an example. To be able to manufacture knowledge capital, however, firms in the intermediate sectors require a blueprint. Blueprints are also assumed to be nonrival but, in contrast to knowledge capital, they are assumed to be only partially excludable. Owners can prevent others from using their blueprints by means of patent protection, but cannot completely prevent the knowledge or experience that is being gained in the R\&D processes from spilling over to other researchers or producers. This partial excludability causes private- and social returns to $R \& D$ to diverge.

There exist multiple institutional structures that support a decentralized equilibrium (Romer, 1990). We like to think of firms manufacturing knowledge capital separate from firms manufacturing final goods. Alternatively, one can think of firms in each production sector manufacturing their type of knowledge capital themselves, i.e. in-house R\&D. As long as knowledge capital is created according to identical innovation possibility frontiers, the institutional structure is irrelevant. Likewise, it is irrelevant whether the innovation and manufacturing of new varieties occurs within departments of one firm or in separate firms as long as these new varieties are manufactured according to identical possibility frontiers and as long as the manufacturing decision is separable from the patent-pricing decision. In either case, the firm that owns the patent extracts the same monopoly profit. We assume that the firm that develops and patents the invention of new varieties of knowledge capital also 
manufactures these new varieties and that he is the sole manufacturer so that there is a one-toone correspondence between inventive firms and varieties of knowledge capital. We therefore characterize manufacturing of knowledge capital in each intermediate sector by a single innovation possibilities frontier that comprises a fixed- and a variable cost component. The fixed costs can be seen as a 'set-up' cost related to the research and development of a blueprint for a new variety of knowledge capital, i.e. innovation, that a firm must incur once in order to be able to produce this new variety of knowledge capital. The variable cost component relates to their manufacturing. Finally, we make the assumptions that manufacturing of knowledge capital is a deterministic process and that aggregate innovation possibility frontiers are continuous, which allows us to avoid problems due to integer variables and uncertainty.

Set-up costs related to R\&D merely involve final goods, and only at the time of entry. RiveraBatiz and Romer (1991) refer to this specification as the lab-equipment specification for its emphasis on physical inputs. As they also point out, this does not mean that final goods are directly converted into blueprints but rather that the inputs necessary for production of final goods are used, in the same proportions, for research and development instead. Formally for sector $i$ :

$$
N_{i, t}=Q_{i, t}-C_{i, t}-\theta_{i}^{I} \cdot I_{t} \quad(t=1, . ., T),(i=X, Y)
$$

where $C_{i, t}$ denotes consumption of $\operatorname{good} i$ and $\theta_{i}^{I}$ is sector $i$ 's share in total investment in physical capital $\left(I_{t}\right)$. Note that this specification implies that R\&D uses energy and knowledge capital indirectly, rather than directly, as inputs.

This is not the complete picture because feedback in TC affects these R\&D costs. ${ }^{c}$ One feedback loop is that all previous $R \& D$ activities have an effect on current $R \& D$, which Rivera-Batiz and Romer refer to as the knowledge-based specification of R\&D. Learning-byresearching and knowledge spillovers underlie this feedback loop. Another feedback loop is that adoption of any variety of knowledge capital in the previous period has an effect on current R\&D. Learning-by-doing, learning-by-using, and an increased market size underlie this feedback loop. These feedback loops operate within each intermediate sector only because we assume the two types of knowledge capital to be too different from each other to benefit form each other's technical changes:

$$
N_{i, t}=N_{i, t-1}^{\xi_{i}} \cdot K C_{i, t-1}^{v_{i}} \cdot\left(Q_{i, t}-C_{i, t}-\theta_{i}^{I} \cdot I_{t}\right) \quad(t=1, . ., T),(i=X, Y)
$$

where $\xi_{i}$ is the feedback effect from last period's stock of blueprints in intermediate sector $i$ $\left(N_{i, t-1}\right)$, and where $v_{i}$ measures the feedback effect from last period's aggregate manufacturing of knowledge capital $i\left(K C_{i, t-1}\right)$. The condition that in equilibrium demand for

\footnotetext{
${ }^{\mathrm{b}}$ Even though indivisibility of blueprints and knowledge capital and uncertainty related to R\&D processes are facts of life, averaging out makes these facts matter less at aggregate levels (Romer, 1990).

${ }^{c}$ For illustrative purposes, we limit ourselves to one-period-delayed feedback.
} 
knowledge capital equals its supply in any given period allows us to express the latter feedback loop in terms of aggregate manufacturing of knowledge capital rather than in terms of its adoption.

Equation 4 reveals several interesting, though not surprising, implications for the rate of innovation of blueprints. First, higher expenditures on $R \& D$ lead to a higher rate of innovation. Second, a higher rate of innovation or diffusion, or both, increases the productivity of resources devoted to $R \& D$. Yet, a third implication is that this increase in productivity does not continue to grow in proportion to the rate of TC if the feedback effects are smaller than one. If this is indeed the case, it might eventually become more productive to devote these $R \& D$ resources elsewhere in the economy.

Once a blueprint has been developed, it is added to its respective stock and is therefore available for more than one period (see equation A.26). Variable costs of manufacturing this new variety of knowledge capital $i$ subsequently comprise costs of labor $\left(L_{i, t}\right)$ and physical capital $\left(K_{i, t}\right)$ in any period. Moreover, adoption of any variety of knowledge capital in the previous period has an effect on current adoption. Consumption externalities and learning-byusing underlie this feedback loop:

$$
Z_{i, t}=K C_{i, t-1}^{\phi_{i}} \cdot K_{i, t}^{\alpha_{i}^{Z}} \cdot L_{i, t}^{1-\alpha_{i}^{Z}} \quad(t=1, . ., T),(i=X, Y)
$$

where $\phi_{i}$ is the feedback effect from last period's adoption of knowledge capital $i$. Figure 1 summarizes the specification of TC in our model.

Figure 1. Specification of technical change

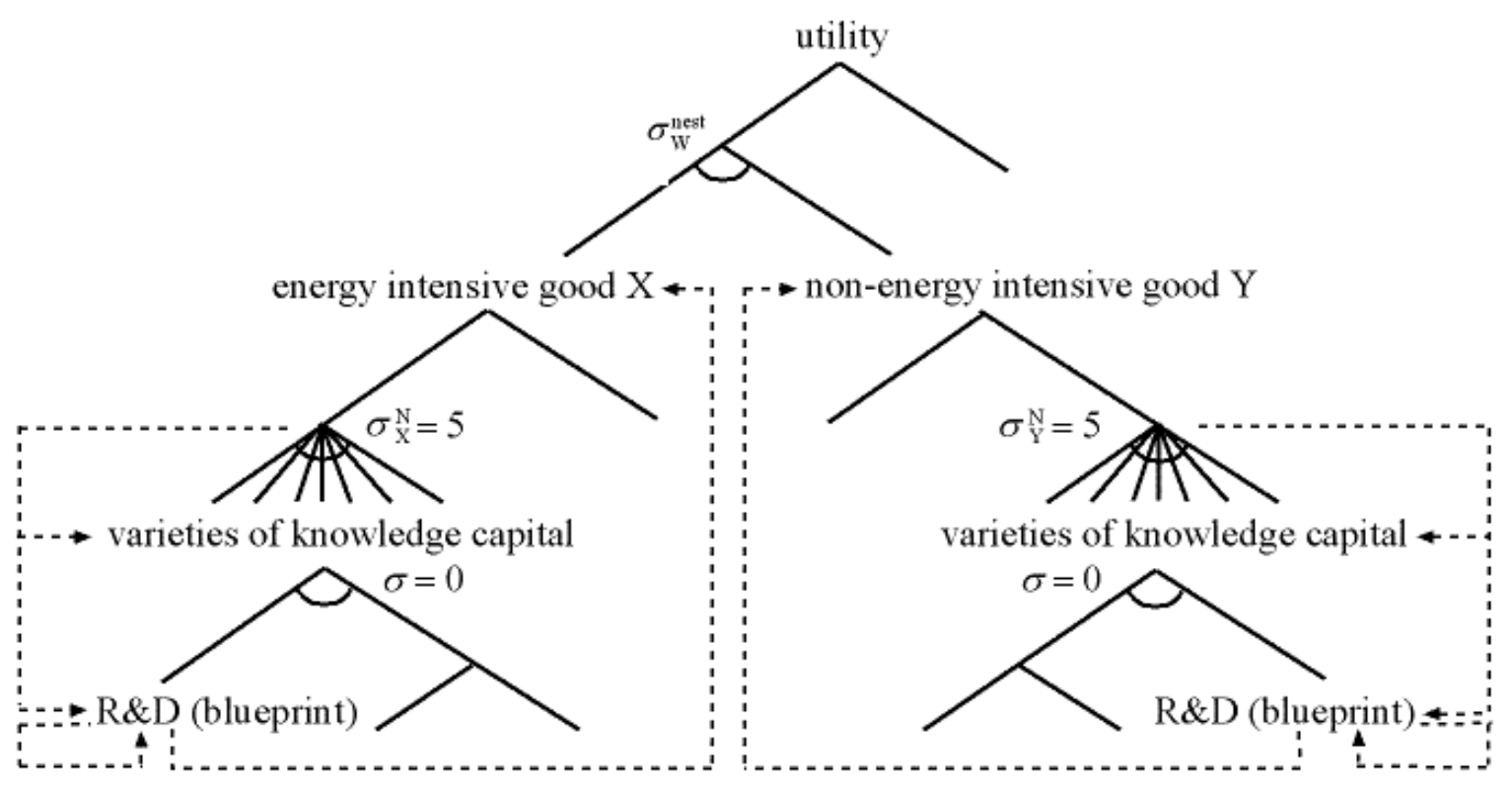


Assuming symmetric cost structures for firms in the intermediate sector ensures that all varieties of knowledge capital are initially supplied at identical levels and allows us to express aggregate output of each intermediate sector in period $t$ as:

$$
K C_{i, t}=\left(N S_{i, t} \cdot Z_{i, t}^{\varphi}\right)^{\frac{1}{\varphi}} \quad \varphi=\frac{\sigma_{i}^{N}-1}{\sigma_{i}^{N}} \quad(t=1, . ., T),(i=X, Y)
$$

where the elasticity of demand for an individual variety, $\varphi$, equals the compensated elasticity of substitution between varieties. This is the usual Chamberlinian large-group assumption in monopolistic competition that determines the height of the constant mark-up over marginal costs. The mark-up, in turn, drives a wedge between the marginal- and average costs of manufacturing knowledge capital and therefore causes the innovation possibilities frontier to be characterized by increasing returns to scale. The feedback loops add to these increasing returns.

Firms in each intermediate sector operate so to maximize their profits over time subject to these innovation possibility frontiers. The increasing returns generate profits in the immediate short-run, which attract new firms. Given that manufacturing knowledge capital is assumed to be a deterministic process, firms can enter freely and have perfect foresight, a new firm will enter at time $t$ if, and only if, the present-value of profits, $V_{i}$, is non-negative. This implies that the present-value of future revenues must be equal to or greater than the set-up costs related to the research and development of a new variety of knowledge capital (suppressing the time subscripts to simplify notation from now on):

$$
V_{i}-\dot{V}_{i} \equiv\left[\frac{Z_{i} \cdot \frac{1}{\sigma_{i}^{N}-1}}{i r} \geq F C\right] \quad(i=X, Y)
$$

where $i r$ is the interest rate and $F C$ are the set-up costs that we both assume to be constant and equal for both sectors. $\dot{V}_{i}$ allows future profits to differ from current ones, which might occur, for example, when moving from one balanced growth path to another. Yet, free entry ensures zero profits in a present value sense in a balanced growth path so that the $\dot{V}$ terms are zero. Moreover, we assume that the elasticity of substitution between varieties of knowledge capital is equal for both types. This allows us to write the relative profitability of developing knowledge capital appropriate for production of $Q_{i}$ as

$$
\frac{V_{Y}}{V_{X}}=\frac{Z_{Y}}{Z_{X}}
$$

To gain further understanding, we substitute the dual form of (6) (see equation A.24) into the market clearance condition for $Z_{i, t}$ (see equation A.25) and rearrange terms to get an expression for the relative demand of $Z_{X}$, which we substitute in (8): 


$$
\frac{V_{Y}}{V_{X}}=\frac{1-\alpha_{Y}^{Q}-\beta_{Y}^{Q}-\chi_{Y}}{1-\alpha_{X}^{Q}-\beta_{X}^{Q}-\chi_{X}} \cdot \frac{P Z_{X}}{P Z_{Y}} \cdot \frac{P Q_{Y}}{P Q_{X}} \cdot \frac{Q_{Y}}{Q_{X}}
$$

We identify four effects. The first term on the right-hand side is the factor-substitution effect: to the extent $K C_{i}$ is substituted for other factors in production, the profitability of developing knowledge capital appropriate for production of $Q_{i}$ increases. The sign of this factorsubstitution effect is ambiguous when the supply of any factor other than knowledge capital decreases. Given the mobility of labor and physical capital across sectors, the sign depends mainly on the knowledge- and energy intensity of production in both sectors, which are not known a priori. Second, feedback has a negative effect on the relative profitability of innovation, as shown by the fact that $V_{i}$ is decreasing in $P Z_{i}$. The sign of this term is ambiguous as it depends on the sign and magnitude of feedback in both intermediate sectors. Finally, we identify price- and market size effects (Acemoglu, 2002). $V_{i}$ is increasing in the goods prices, $P Q_{i}$, confirming that there is an incentive to develop technologies appropriate for the production of more expensive goods. $V_{i}$ is also increasing in $Q_{i}$, confirming that there simultaneously is an incentive to develop technologies for which there is a greater market. Remember from (2) that the law of demand implies that a change in relative market sizes induces a price effect as well, leaving net effects ambiguous for now.

To investigate the relative strength of the price-and market size effects, we follow Acemoglu by substituting the relative price of both goods, (2), into (9):

$$
\frac{V_{Y}}{V_{X}}=\frac{1-\alpha_{Y}^{Q}-\beta_{Y}^{Q}-\chi_{Y}}{1-\alpha_{X}^{Q}-\beta_{X}^{Q}-\chi_{X}} \cdot\left(\frac{\theta_{X}^{C}}{1-\theta_{X}^{C}}\right)^{\frac{1}{-\sigma_{W}^{n \text { eest }}}} \cdot \frac{P Z_{X}}{P Z_{Y}} \cdot\left(\frac{Q_{Y}}{Q_{X}}\right)^{\frac{1-\sigma_{W}^{\text {nest }}}{-\sigma_{W}^{\text {nest }}}}
$$

This expression shows that the elasticity of substitution between both goods is a determinant of the direction of TC as it regulates the relative strength of the price-and market size effects. The less substitutable goods are, the more scarcity commands higher prices and the more powerful the price effect gets relative to the market-size effect. If both goods are gross complements $\left(\sigma_{W}^{n e s t}<1\right)$, we expect a decrease in the relative supply of a good to increase its relative price and profitability so that the price effect dominates. If both goods are gross substitutes $\left(\sigma_{W}^{\text {nest }}>1\right)$ we expect a decrease in the relative supply of a good to decrease its profitability so that the market-size effect dominates. If both goods have unitary substitution elasticity, we expect both effects to balance.

In addition to showing the relative strength of the price- and market-size effect, expression (9) reveals a new term capturing consequences of the usual substitution effect for the relative profitability of innovation. Substitution of one good for the other in consumption increases demand for the substituting good and hence the profitability of developing technologies that 
are appropriate for production of the substituting good, ceteris paribus, as shown by the fact that $V_{i}$ is increasing in $\theta_{i}^{C}$.

In sum, we identify the substitution elasticity between both goods as well as feedback in TC as two key determinants of the equilibrium bias in TC, although net effects are ambiguous. What the equilibrium bias amounts to is what we turn to in our simulation exercise.

\section{Simulations}

We illustrate the model with three simulations. First, we introduce environmental policy and assume both goods to be gross complements $\left(\sigma_{W}^{\text {nest }}<1\right)$, e.g. electricity versus electronic equipment. Second, we introduce environmental policy and assume both goods to be gross substitutes $\left(\sigma_{W}^{\text {nest }}>1\right)$, e.g. electricity generated with oil versus electricity generated with wind. Finally, we introduce environmental policy and assume both goods to be gross substitutes while there is feedback in TC. We assume positive feedback such that researchers stand on the shoulders of their predecessors. We exclude the possibility of e.g. negative spillovers or 'organizational forgetting' by restricting the positive feedback to take on positive values only. Emission rights are associated to energy use and environmental policy takes the form of 25 percent fewer emission rights being allocated relative to a reference case. We calibrate the model to a balanced growth path of two percent that serves as the reference case. In this reference case, markets for blueprints are monopolistically competitive. We consider a 26-year time horizon, defined over the years 2005 through 2030. We use illustrative data and parameters as reported in Tables 1 and 2.

Table 1. Social accounting matrix

\begin{tabular}{|c|c|c|c|c|c|c|c|c|c|c|}
\hline & \multicolumn{8}{|c|}{ Zero profits } & \multirow{2}{*}{$\begin{array}{l}\text { Income balance } \\
M\end{array}$} \\
\hline & & $Q_{X}$ & $Z_{X}$ & $N_{X}$ & $Q_{Y}$ & $Z_{Y}$ & $N_{Y}$ & $I$ & $W$ & \\
\hline \multirow{10}{*}{ 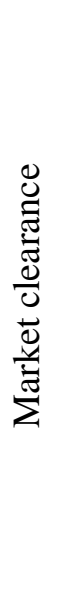 } & $P Q_{X}$ & 300 & & -8 & & & & -105 & -187 & \\
\hline & $P Q_{Y}$ & & & & 220 & & -8 & -28 & -184 & \\
\hline & $P K C_{X}$ & -100 & 100 & -12 & & & & & & 12 \\
\hline & $P K C_{Y}$ & & & & -100 & 100 & -12 & & & 12 \\
\hline & $P F C_{X}$ & & & & & -20 & 20 & & & \\
\hline & $P F C_{Y}$ & & -20 & 20 & & & & & & \\
\hline & $P W$ & & & & & & & 133 & 431 & -564 \\
\hline & $P L$ & -30 & -20 & & -90 & -60 & & & -60 & 260 \\
\hline & $R K$ & -90 & -60 & & -20 & -20 & & & & 190 \\
\hline & $P E$ & -80 & & & -10 & & & & & 90 \\
\hline
\end{tabular}

Note: numbers are in value terms. 
Table 2. Parameter values

\begin{tabular}{|c|c|c|c|c|}
\hline \multirow{2}{*}{ Description } & \multirow{2}{*}{ Symbol } & \multicolumn{3}{|c|}{ Value per Simulation } \\
\hline & & 1 & 2 & 3 \\
\hline Growth rate & $g$ & 0.02 & 0.02 & 0.02 \\
\hline \multicolumn{5}{|l|}{ Depreciation rates } \\
\hline Physical capital & $\delta^{K}$ & 0.05 & 0.05 & 0.05 \\
\hline Blueprints & $\delta_{i}^{N}$ & 0.2 & 0.2 & 0.2 \\
\hline Degree of homogeneity in knowledge capital & $r_{i}^{P K C}$ & 1.25 & 1.25 & 1.25 \\
\hline \multicolumn{5}{|l|}{ Substitution elasticities } \\
\hline $\begin{array}{l}\text { Between the composite good and leisure in } \\
\text { instantaneous utility }\end{array}$ & $\sigma_{W}$ & 0.5 & 0.5 & 0.5 \\
\hline Between goods $X$ and $Y$ in instantaneous utility & $\sigma_{W}^{n e s t}$ & 0.75 & 2 & 2 \\
\hline $\begin{array}{l}\text { Between varieties in aggregate production of } \\
\text { knowledge capital }\end{array}$ & $\sigma_{i}^{N}$ & 5 & 5 & 5 \\
\hline \multicolumn{5}{|l|}{ Feedback effects } \\
\hline From diffusion to diffusion & $\phi_{i}$ & 0 & 0 & 0.15 \\
\hline From diffusion to $\mathrm{R} \& \mathrm{D}$ & $v_{i}$ & 0 & 0 & 0.15 \\
\hline From $R \& D$ to $R \& D$ & $\xi_{i}$ & 0 & 0 & 0.15 \\
\hline Knowledge spillovers to production & $\gamma_{i}$ & 0.15 & 0.15 & 0.15 \\
\hline \multicolumn{5}{|l|}{ Policies } \\
\hline Reduction in emission rights & er & 0.25 & 0.25 & 0.25 \\
\hline
\end{tabular}

Note: Simulation BM refers to the benchmark or reference case; simulation 1 to fewer emission rights while both goods are gross complements; simulation 2 to fewer emission rights while both goods are gross substitutes; simulation 3 to fewer emission rights while both goods are gross substitutes and while there is positive feedback in technical change.

For each simulation, we compare model results to the reference case where variables are reported as percentage changes from their reference case values. We compare outcomes with respect to (i) welfare of the representative consumer as measured by Hicksian equivalent variation, (ii) the structure of the economy as measured by consumption levels of both goods, and (iii) the rate and direction of TC as indicated by the amount of knowledge capital adopted in each intermediate sector (diffusion) as well as the concomitant number of blueprints required (innovation).

\section{Simulation 1: fewer emission rights when both goods are gross complements}

We consider the effects of granting 25 percent fewer emission rights annually, relative to the reference case, while both goods are gross complements of each other. One can think of these goods as electricity and electronic equipment. There is a limited possibility to substitute more efficient electronic equipment for electricity while generation of electricity requires relatively more energy as input than manufacturing of electronics.

Figure 2 shows that the reduction in allocated emission rights leaves the representative consumer worse off in terms of welfare. The limited possibility to substitute final goods 
allows the representative consumer to a certain extent to adjust to the policy. Yet, the allocation of fewer emission rights shifts the supply curve of the energy-intensive good upward, ceteris paribus, giving rise to a negative income effect as well as a deadweight loss that outweigh the substitution effect.

Figure 2. Equivalent variation in each simulation

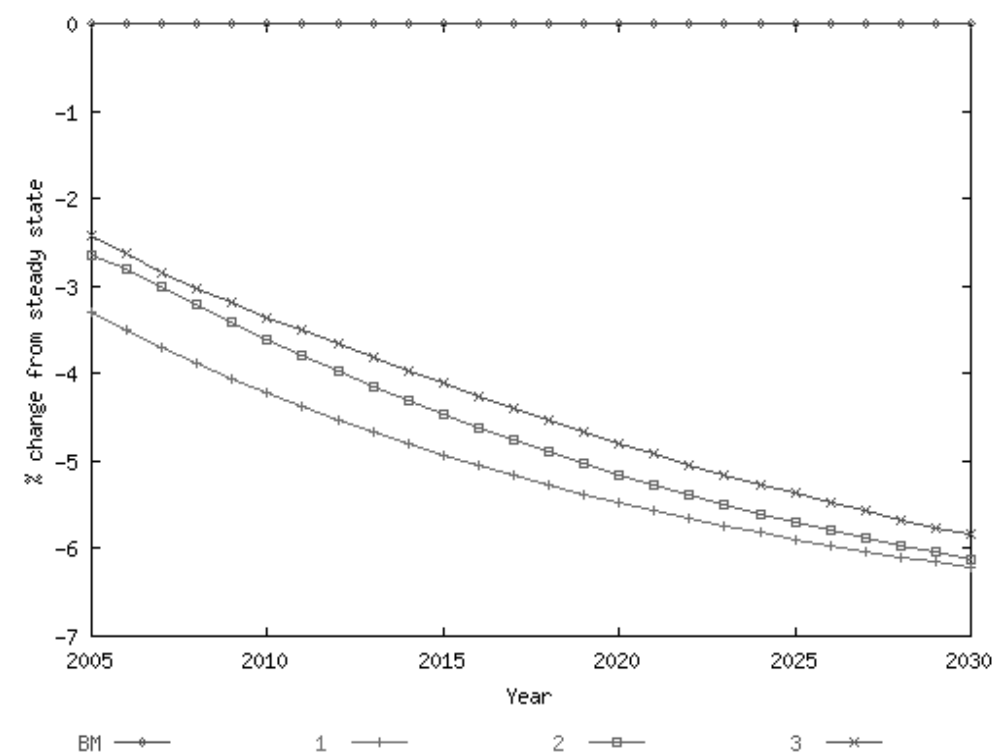

Figure 3 shows that the reduced welfare translates into lower consumption levels of each good, relative to the reference case. Further, consumption levels of good $X$ fall more than those of good $Y$ as the representative consumer substitutes a limited amount of good $Y$ for $\operatorname{good} X$.

Figure 3. Effects of fewer emission rights on consumption while both goods are gross complements

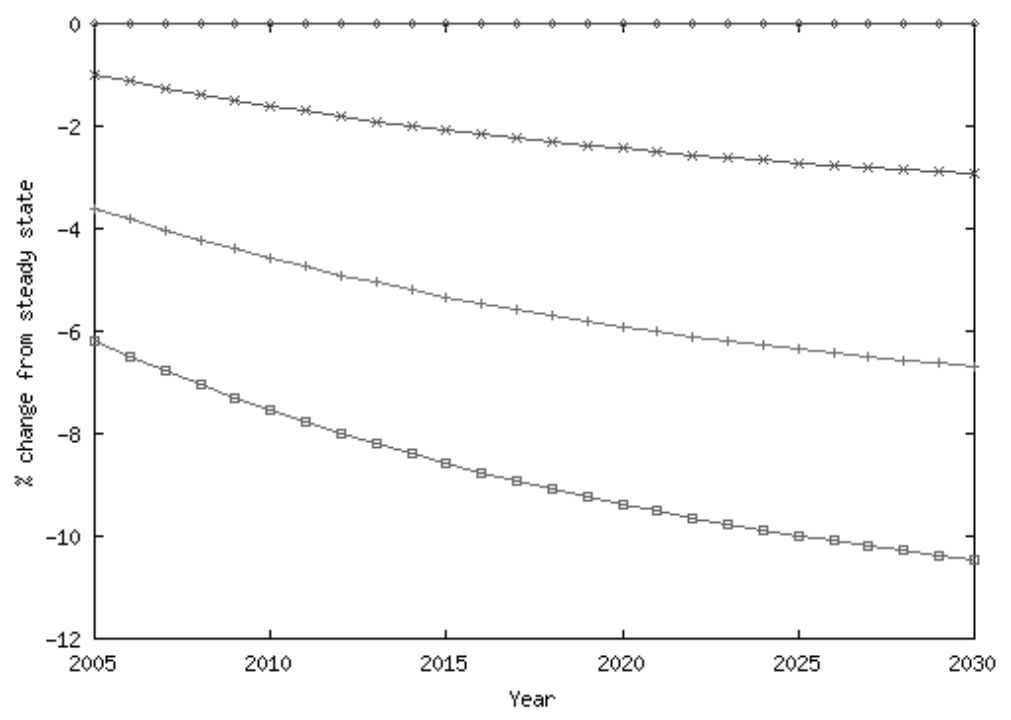

$\mathrm{BM} \longrightarrow \quad \mathrm{C} \longrightarrow \quad \mathrm{CX} \longrightarrow \quad \mathrm{CY} \longrightarrow$ 
Figure 4 shows the effects of the reduction in allocated emission rights on diffusion in each sector. The moment the policy is introduced, aggregate demand for knowledge capital increases slightly because of the factor-substitution effect. The stock of blueprints in the economy is still high relative to its new equilibrium level causing knowledge capital to be a relatively cheap input to production, ceteris paribus. However, aggregate demand for knowledge capital falls in concordance with welfare and aggregate consumption as soon as blueprints depreciate and the stock approaches its new equilibrium level.

Figure 4. Effects of fewer emission rights on diffusion while both goods are gross complements

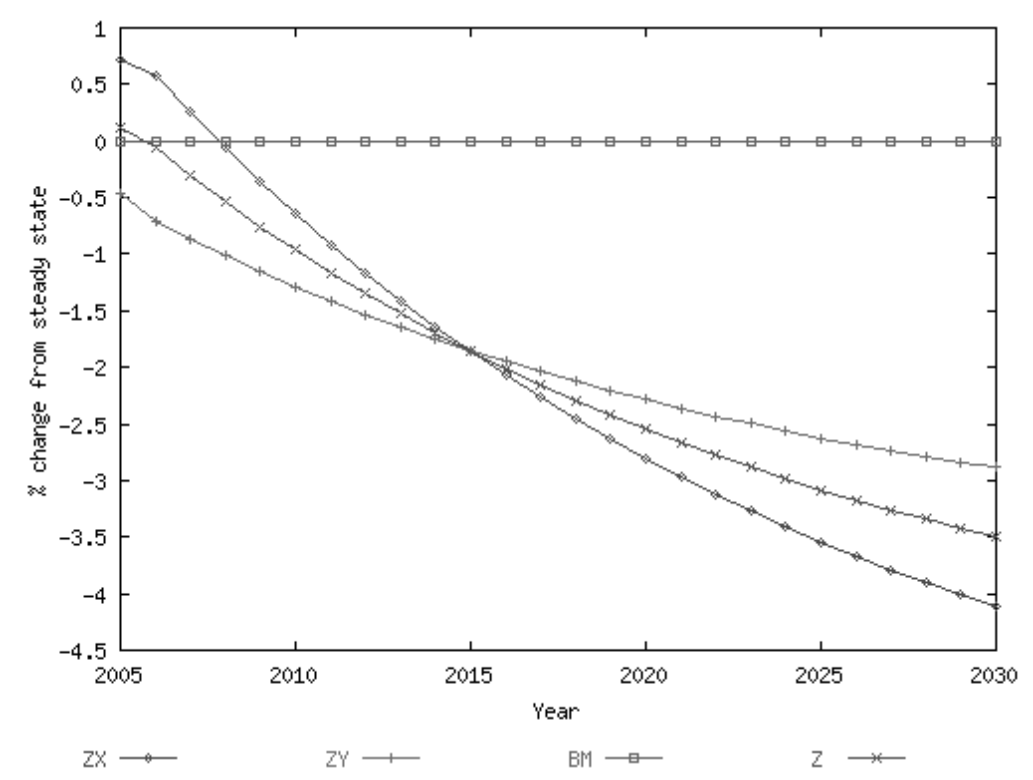

With respect to the equilibrium bias in diffusion, this factor-substitution effect is stronger for the energy-intensive good $X$. Therefore, more knowledge capital is substituted for emission rights in the production of good $X$, leaving us with a corresponding bias in innovation. Further, allocating fewer emission rights indirectly changes the relative scarcity of both goods, leading to the price- and market-size effects discussed in Section 2. Limited substitution possibilities between both goods ensure that it now becomes more profitable to develop and manufacture knowledge capital appropriate for production of the relatively scarce good $X$ causing the price effect to outweigh the market size effect, ceteris paribus. In a partial equilibrium setting, this would leave us with an equilibrium bias toward the relatively energy-intensive and therefore scarce good $X$. When thinking of these goods as electricity and electronics, the higher cost of energy use implies that especially the electricity producers are induced to invest in energy-saving technology. In our CGE setting, however, we find that the substitution effect reinforces the market size effect to the extent that it leaves us with an equilibrium bias in diffusion toward the non-energy intensive sector $Y$. The representative consumer, for example, shifts away from electricity toward more efficient electronics, which 
leaves manufacturers of electronics with an incentive to adopt more knowledge capital to increase their productivity as to meet this increased demand for more efficient electronics.

Figure 5 shows the concomitant change in innovation. Rates of research and development are immediately adjusted to the lower demands for knowledge capital. With respect to the equilibrium bias, innovation is immediately biased toward the non-energy intensive sector $Y$, as the factor-substitution effect is smaller for innovation than it is for diffusion. The difference lies in the initial excess supply of old blueprints that causes this effect to be relatively strong for diffusion. Thus, the price- and factor-substitution effects are not strong enough to outweigh the substitution- and market-size effects with respect to innovation. It can be shown that the price- and factor-substitution effects are strong enough to outweigh the market-size effect if, and only if, the substitution effect is absent, i.e. if both goods are strictly complementary.

Figure 5. Effects of fewer emission rights on innovation while both goods are gross complements

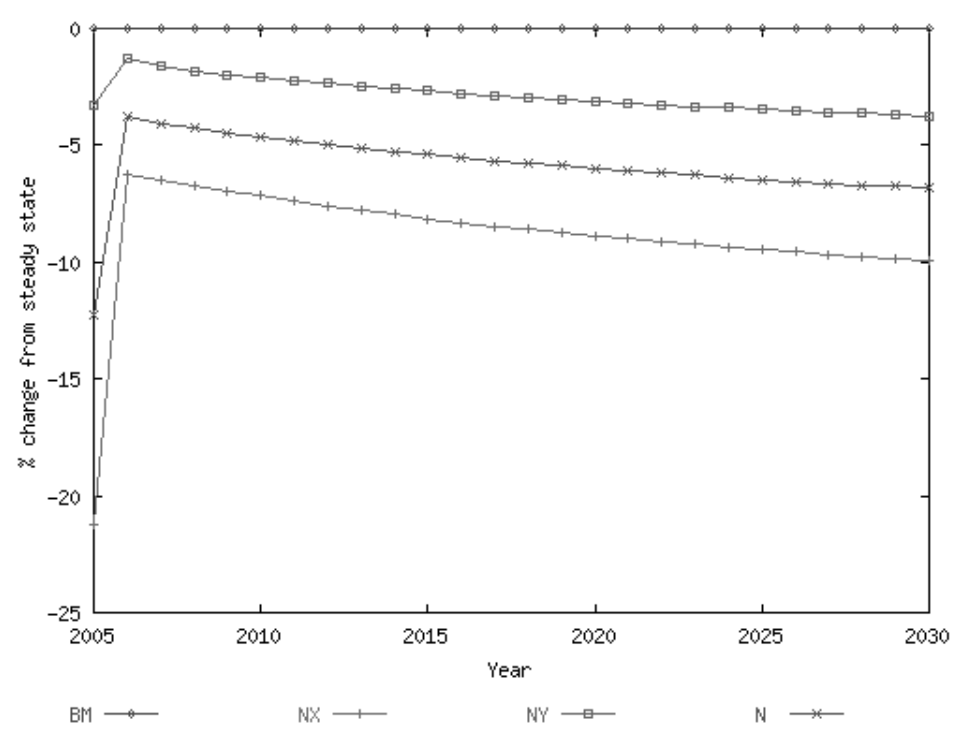

Simulation 2: fewer emission rights when both goods are gross substitutes

We next consider the effects of the same policy but allow for more substitutability between both goods. One can think of electricity generated with oil versus electricity generated with wind. There are now more possibilities to substitute both goods, as electricity is more or less a homogeneous good, while generation with oil requires more fuel energy as input than generation with wind. For now, we assume that there is no feedback in TC.

Figure 2 shows that welfare levels are higher relative to the previous simulation as the increased substitution possibility allows the representative consumer to better adjust to the policy. Relative to the reference case, however, the policy still lowers welfare as the deadweight loss and negative income effect outweigh the substitution effect. As a result, 
aggregate consumption remains lower in each period, relative to the reference case, although the representative consumer now substitutes good $Y$ for good $X$ to the extent that the consumption level of good $Y$ increases relative to the reference case (see Figure 6).

Figure 6. Effects of fewer emission rights on consumption while both goods are gross substitutes, with and without positive feedback (F)

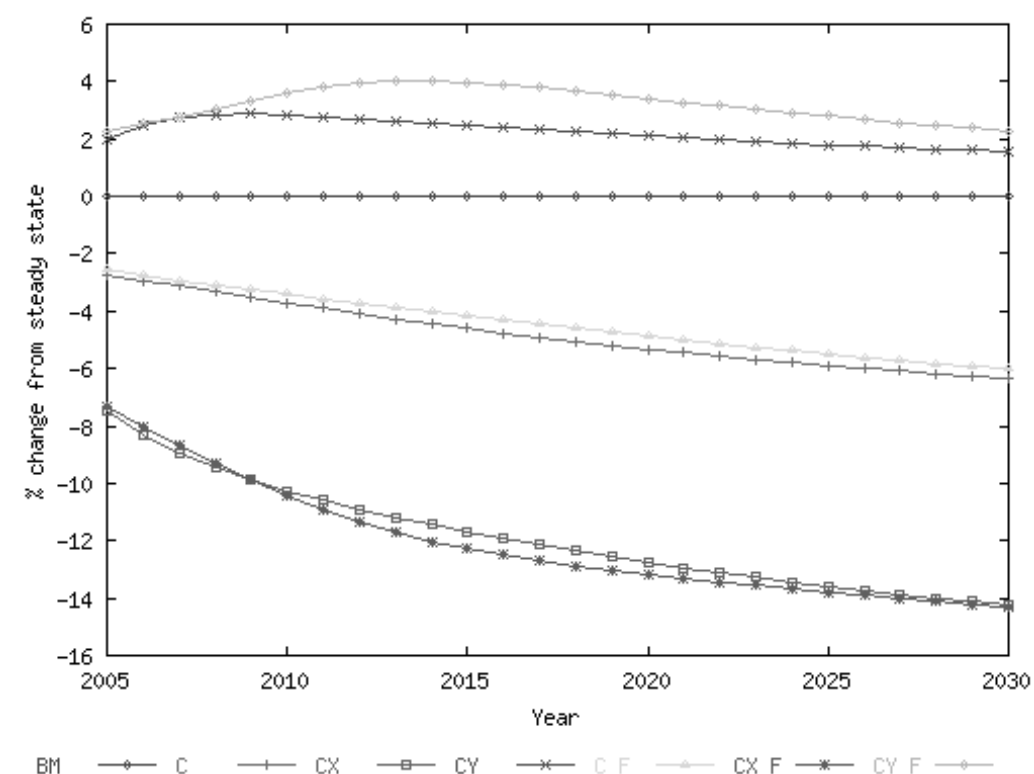

As in the previous simulation, the rate of aggregate diffusion decreases from the moment the policy is introduced as shown in Figure 7.

Figure 7. Effects of fewer emission rights on diffusion while both goods are gross substitutes, with and without positive feedback $(\mathrm{F})$

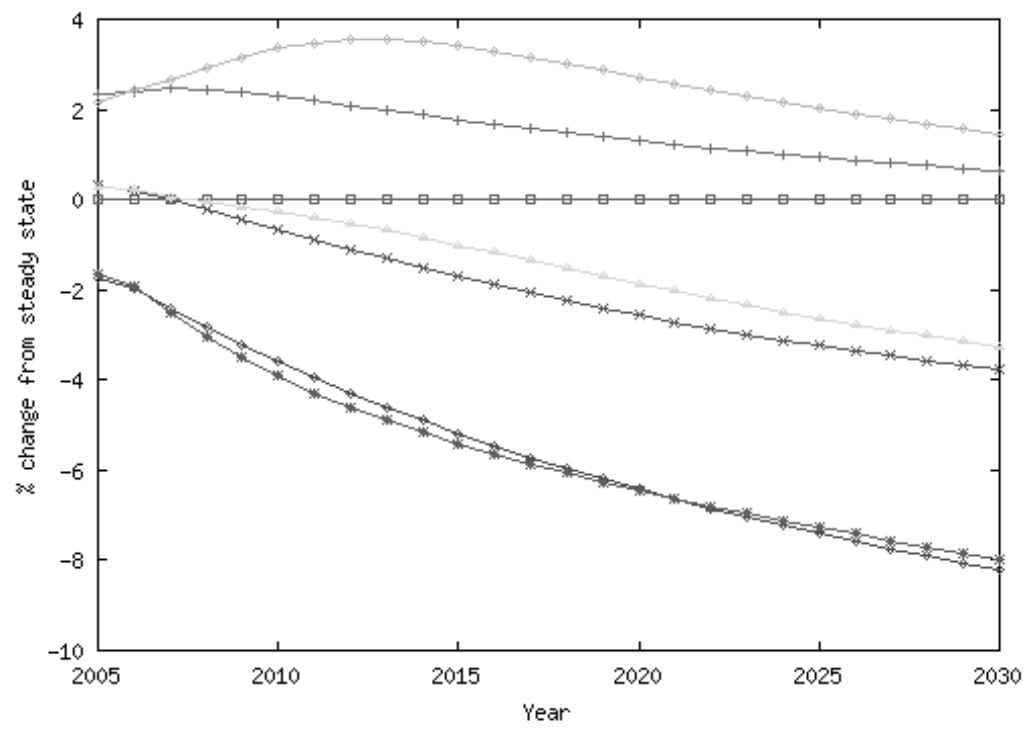

$Z X \longrightarrow Z Y \longrightarrow B M \longrightarrow Z \longrightarrow Z F \longrightarrow Z X F \rightarrow Z Y=Z$ 
Unlike in the previous simulation, however, the rate of diffusion in the non-energy intensive sector $Y$ now increases relative to the reference case. This increase comes at the expense of diffusion of knowledge capital appropriate for the energy-intensive sector $X$, whose rate of diffusion is now considerably lower than in the previous simulation. As electricity is generated with more wind instead of oil, for example, electricity producers using wind turbines demand more knowledge capital while those who use oil-fired power plants demand less. One reason behind this stronger equilibrium bias toward the non-energy intensive sector $Y$, relative to the previous simulation, is that the market-size effect outweighs the price effect when the goods are gross substitutes. Another reason is that the increased substitution possibilities strengthen the substitution effect - more of the relatively abundant good $Y$ is substituted for the relatively scarce good $X$ - that in turn translates into a relatively higher demand for knowledge capital $Z Y$, ceteris paribus.

Producers of electricity using wind turbines, for example, are especially induced to invest in knowledge capital as to meet the increased demand for electricity from wind. Figure 8 shows similar trends for concomitant innovation in both sectors.

Figure 8. Effects of fewer emission rights on innovation while both goods are gross substitutes, with and without positive feedback (F)

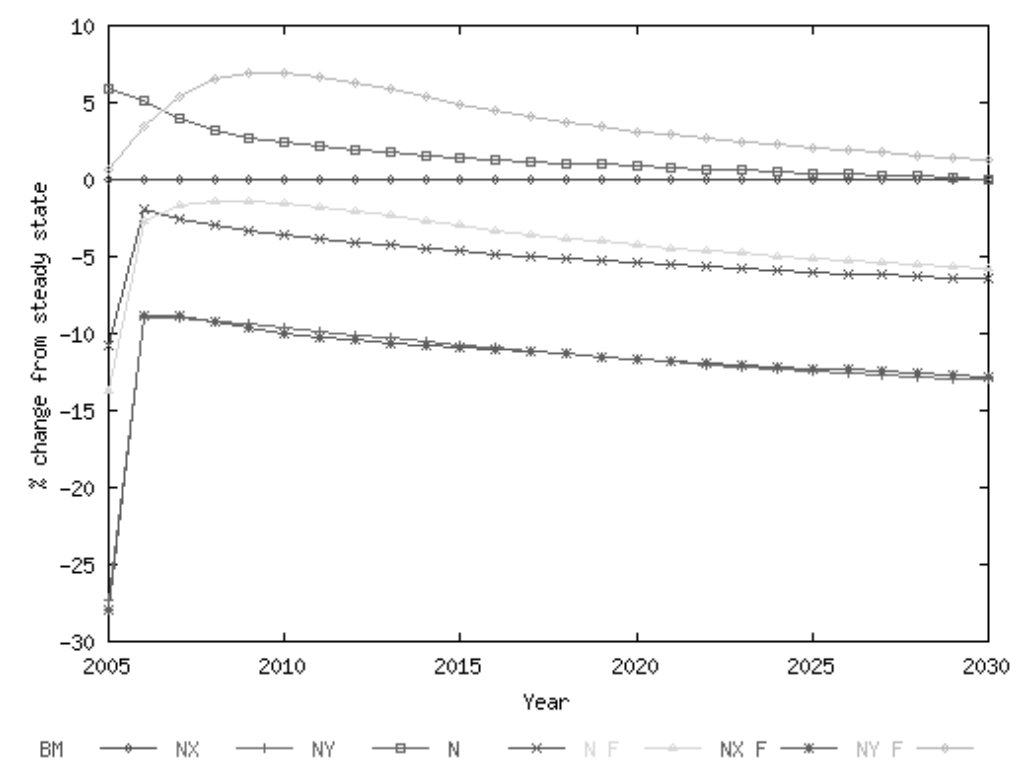

Simulation 3: fewer emission rights when there is positive feedback in technical change

We now build on the previous simulation and allow for positive feedback. Thus, we still assume both goods to be gross substitutes of each other. Presence of positive feedback makes the economy more elastic in that a given policy leads to greater adjustments in the economy, as already pointed out by Goulder and Schneider (1999). Hence, it should come as no surprise that the results of the previous simulations are accentuated by the positive feedback (see 
Figures 4 and 5) but that their effects are nonetheless ascribable to the main effect of allocating fewer emission rights. The equilibrium bias in diffusion is a good example. Presence of positive feedback reinforces this equilibrium bias because the more producers adopt knowledge capital $Z Y$, relative to $Z X$, the less costly it becomes for other producers to adopt knowledge capital $Z Y$, relative to $Z X$. For producers of electricity using wind turbines, for example, it becomes less costly to adopt knowledge capital as the value associated to its use increases.

Welfare levels are higher, relative to the previous simulation without positive feedback, because of the external benefits associated with positive feedback (see Figure 2). Yet, welfare levels remain below the reference case. Besides the distortionary nature of the policy, a main reason is that too few resources are allocated to the intermediate sectors from a social point of view.

\section{Sensitivity Analysis}

To gain further understanding of the model, we perform 'piecemeal' sensitivity analyses. We use central parameter values in all simulations (see Table 2) except for the parameter subject to analysis. We furthermore examine the sensitivity of the model to the policy in place. We report effects on the relative profitability of knowledge capital in each sector, as defined in equations (8)-(10), and on intertemporal utility. Both variables are reported in present values. Table 3 presents the results. Allocating 50 percent fewer emission rights, instead of the regular 25 percent, causes greater welfare losses. It biases TC even more in the direction of the non-energy intensive good. The opposite holds if we halve the reduction in emission rights. Halving the substitution elasticity between varieties of knowledge capital translates into higher mark ups over marginal costs of manufacturing knowledge capital, which attracts more firms to the intermediate sectors. The additional blueprints that are henceforth developed can substitute for more emission rights in production and generate additional external benefits. The upshot is that welfare losses associated with the policy are slightly smaller and that TC gets biased even more toward the non-energy intensive sector. The opposite holds if we double the substitution elasticity between varieties. Doubling the depreciation rate on knowledge capital raises the opportunity costs of resources devoted to $\mathrm{R} \& \mathrm{D}$ and leads to greater welfare losses, all else equal. A higher depreciation rate also leads to a smaller stock of knowledge capital and therefore higher prices and lower profits (see equation (10)). At the same time, however, the additional $R \& D$ that is now being undertaken generates external benefits in the form of the positive feedback from innovation to innovation. Therefore, net decrease in welfare is small. This effect is slightly stronger for the non-energy intensive sector that benefits from the policy, as TC is already biased toward this sector. The opposite holds if we halve the depreciation rate. 
Table 3. Piecemeal sensitivity analysis

\begin{tabular}{|c|c|c|c|c|c|c|}
\hline \multirow[t]{3}{*}{ Simulation } & \multicolumn{3}{|c|}{$\begin{array}{l}\text { Relative profitability of TC: } \\
\qquad V_{Y} / V_{X}\end{array}$} & \multicolumn{3}{|c|}{$\begin{array}{c}\text { Utility: } \\
\text { U }\end{array}$} \\
\hline & \multicolumn{3}{|c|}{ Simulation } & \multicolumn{3}{|c|}{ Simulation } \\
\hline & 1 & 2 & 3 & 1 & 2 & 3 \\
\hline Regular simulation & 1.004 & 1.079 & 1.090 & 0.947 & 0.951 & 0.954 \\
\hline \multicolumn{7}{|l|}{ Policies } \\
\hline$e r_{t}$ halved & 1.002 & 1.036 & 1.041 & 0.975 & 0.977 & 0.978 \\
\hline$e r_{t}$ doubled & 1.010 & 1.201 & 1.232 & 0.877 & 0.888 & 0.895 \\
\hline \multicolumn{7}{|l|}{ Model parameters } \\
\hline$\sigma_{i}^{N}$ halved & 1.005 & 1.101 & 1.196 & 0.949 & 0.955 & 0.972 \\
\hline$\sigma_{i}^{N}$ doubled & 1.003 & 1.075 & 1.079 & 0.946 & 0.949 & 0.951 \\
\hline$\delta_{i}^{N}$ halved & 1.004 & 1.083 & 1.099 & 0.947 & 0.952 & 0.955 \\
\hline$\delta_{i}^{N}$ doubled & 1.004 & 1.077 & 1.085 & 0.947 & 0.950 & 0.952 \\
\hline$\gamma_{i}$ halved & & & 1.087 & & & 0.952 \\
\hline$\gamma_{i}$ doubled & & & 1.118 & & & 0.966 \\
\hline$\phi_{i}$ halved & & & 1.086 & & & 0.953 \\
\hline$\phi_{i} \quad$ doubled & & & 1.118 & & & 0.959 \\
\hline$v_{i}$ halved & & & 1.088 & & & 0.953 \\
\hline$v_{i}$ doubled & & & 1.099 & & & 0.956 \\
\hline$\xi_{i} \quad$ halved & & & 1.087 & & & 0.953 \\
\hline$\xi_{i}$ doubled & & & 1.111 & & & 0.959 \\
\hline
\end{tabular}

Notes: All figures are present values and indices relative to the reference case. Simulation BM refers to the reference case; simulation 1 to fewer emission rights while both goods are gross complements; simulation 2 to fewer emission rights while both goods are gross substitutes; simulation 3 to fewer emission rights while both goods are gross substitutes and while there is positive feedback in technical change (TC).

Finally, we examine the sensitivity of the model to the positive feedback in TC. Doubling any of these parameters leads to smaller welfare losses associated to the environmental policy as more external benefits are generated. Profits in the intermediate sectors also increase and TC gets even more biased toward the non-energy intensive sector that benefits from the policy. Again, the opposite holds if we halve any of these parameters.

Given that we identified both the substitution elasticity between both goods and feedback in TC as key determinants of the equilibrium bias in TC, we are particularly interested in the sensitivity of the relative profitability of TC to a combination of these model parameters. This reveals what the overall equilibrium bias amounts to in our model.

Figure 9 confirms that the equilibrium bias in TC shifts away from the energy-intensive sector as both goods become substitutable. It also confirms that the positive feedback intensify the shifts in the equilibrium bias. This intensifying effect is absent when both goods are gross complements (remember that we restricted the positive feedback to take on positive values only), but increases when both goods are more substitutable. If we increase both model 
parameters simultaneously, the model can become unstable. It subsequently tends to a corner solution in which only knowledge capital will be developed and manufactured that is appropriate for the non-energy intensive sector $Y$.

Figure 9. Overall equilibrium bias in innovation

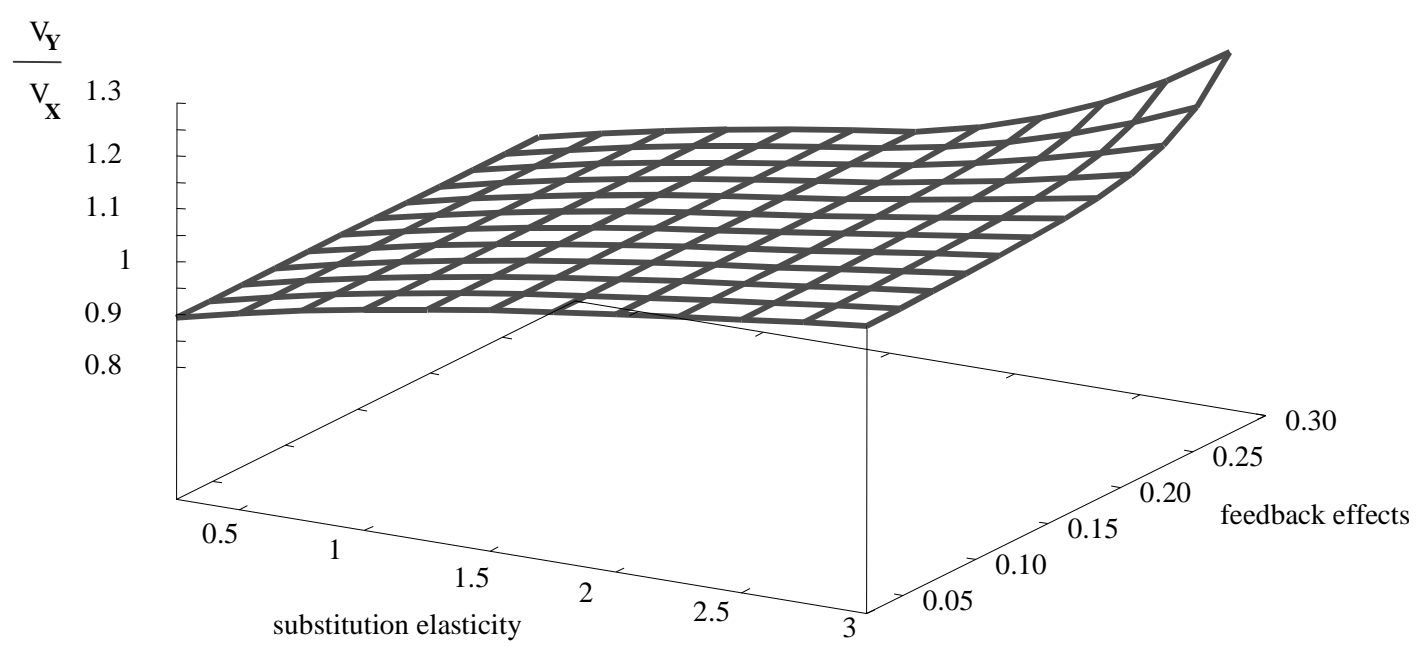

\section{Conclusions}

In this paper, we presented a CGE model that explicitly captures connections between energy, the rate and direction of TC, and the economy. We incorporated Acemoglu's (2002) framework on biased TC and derived determinants of the equilibrium bias. We illustrated the model with three simulations, in which we reduce the number of allocated emission rights associated to energy use.

We find that feedback in TC, substitution possibilities between final goods, and general equilibrium effects are key determinants of the equilibrium bias in TC. We confirm Acemoglu's finding that TC is biased toward the relatively abundant good (non-energy intensive) if the final goods are gross substitutes and that TC is biased toward the relatively scarce good (energy intensive) if the final goods are gross complements. However, in our CGE setting we find that the usual substitution effect reinforces the market size effect causing an equilibrium bias in TC toward the non-energy intensive good even when both goods are gross complements. If, and only if, the substitution effect is absent is the price effect strong enough to outweigh the market-size effect. The equilibrium bias toward the non-energy intensive good is more pronounced if positive feedback occurs in TC. If both goods are very close substitutes, or if the positive feedback effect is strong, or both, the model can yield a corner solution in which only knowledge capital is developed and manufactured that is appropriate for production of the non-energy intensive good.

All this is of public concern. The more substitution possibilities exist between the final goods, the less the environmental policy reduces welfare and the rate of TC. If the substitution 
elasticity is sufficiently large, or the positive feedback is strong enough, or both, environmental policy might even raise the rate of TC in the non-energy intensive sector relative to the reference case. Regarding the positive feedback in TC, a case for policy intervention arises as social returns to $R \& D$ diverge from the private returns to the extent that such feedback is external to agents' decision-making processes. A case for directed policy intervention arises if feedback effects differ between sectors.

There are several ways forward. One is to pay close attention to the model parameters. As the model results depend to a large extent on the substitution elasticity and the feedback effect, special care should be taken to obtain precise estimates of these parameter values before recommending precise regulatory measures. Another is to study the extent to which feedback in TC is specific to various technologies or industries. If, for example, such feedback were to be specific rather than generic, then a regulatory measure would have different impacts across industries. We might then find that the lower welfare costs of policy intervention promised by several studies on induced TC are altered altogether by the feedback. We believe that the model presented in this paper offers a useful framework to study such questions on policy intervention, the rate and direction of TC and the economy. 


\section{Appendix. Structure of the numerical model}

The appendix provides an algebraic summary of the model. It is formulated as a mixedcomplementarity problem (MCP) using the Mathematical Programming System for General Equilibrium Analysis (MPSGE) (Rutherford, 1999), which is a subsystem of the General Algebraic Modeling System (GAMS) (Ferris and Munson, 2000). In this approach, three classes of equilibrium conditions characterize an economic equilibrium: zero-profit conditions for constant-returns-to-scale production activities, market clearance conditions for each primary factor and produced good, and an income definition for the representative consumer. The fundamental unknowns of the system are activity levels, market prices, and the income level. The zero profit conditions exhibit complementary slackness with respect to associated activity levels, the market clearance conditions with respect to market prices, and the income definition equation with respect to the income of the representative consumer. The orthogonality symbol, $\perp$, associates variables with complementary slackness conditions. Differentiating profit and expenditure functions with respect to input and output prices provides compensated demand and supply coefficients (Hotelling's lemma), which appear subsequently in the market clearance conditions. An equilibrium allocation determines production levels, relative prices, and incomes. The price of intertemporal utility is chosen as the numeraire and all prices are reported in present values.

The model is solved for a finite number of time periods. To avoid that the complete stocks of physical capital and blueprints will be consumed in the last period, transversality conditions are necessary. We follow Lau, Pahlke and Rutherford (2002) by constraining the growth rates of investments in the last period to the growth rate of a quantity-variable -in this case instantaneous utility. The advantage of these transversality conditions is that they impose balanced growth but neither specific stocks nor specific growth rates in the last period. This condition therefore suits models in which growth rates are endogenously specified.

\section{Zero profit conditions}

$$
\begin{array}{ccc}
\frac{R K_{t}^{\alpha_{i}^{Q}} \cdot P L_{t}^{\beta_{i}^{Q}} \cdot P E_{t}^{\chi_{i}} \cdot P K C_{i, t}^{1-\alpha_{i}^{Q}-\beta_{i}^{Q}-\chi_{i}}}{N S_{i, t}^{\gamma_{i}}} \geq P Q_{i, t} & \perp Q_{i, t} & i=X, Y ; t=1, . ., T \\
\frac{R K_{t}^{\alpha_{i}^{Z}} \cdot P L_{t}^{1-\alpha_{i}^{Z}}}{K C_{i, t-1}^{\phi_{i}}} \geq P Z_{i, t} \cdot\left(1-1 / \sigma_{i}^{N}\right) & \perp Z_{i, t} & i=X, Y ; t=1, . ., T \\
P N_{i, t}=P F C_{i, t}+\left(1-\delta_{i}^{N}\right) \cdot P N_{i, t+1} & \perp N S_{i, t} & i=X, Y ; t=1, . ., T-1 \\
P N_{i, T}=P F C_{i, T}+P N T_{i} & \perp N S_{i, T} & i=X, Y \\
N_{i, t-1}^{\xi_{i}} \cdot K C_{i, t-1}^{v_{i}} \cdot P Q_{i, t}=P N_{i, t+1} & \perp N_{i, t} & i=X, Y ; t=1, . ., T-1
\end{array}
$$


(A.5)

$$
N_{i, T-1}^{\xi_{i}} \cdot K C_{i, T-1}^{v_{i}} \cdot P Q_{i, T}=P N T_{i}
$$

$$
\perp N_{i, T}
$$$$
i=X, Y
$$

$$
P K_{t}=R K_{t}+\left(1-\delta^{K}\right) \cdot P K_{t+1}
$$

$\perp K_{t}$$$
P K_{T}=R K_{T}+P K T\left[^{6}\right.
$$

(A.6)

$$
\sum_{i=X, Y} \theta_{i}^{I} \cdot P Q_{i, t}=P K_{t+1}
$$

$\perp I_{t}$

$$
t=1, . ., T-1
$$

$$
\sum_{i=X, Y} \theta_{i}^{I} \cdot P Q_{i, T}=P K T
$$

$$
\left[\theta_{C}^{W} \cdot P C_{t}^{1-\sigma_{W}}+\left(1-\theta_{C}^{W}\right) \cdot P L_{t}^{1-\sigma_{W}}\right]^{\frac{1}{1-\sigma_{W}}} \geq P W_{t}
$$

(A.7) with $P C_{t}=\left[\theta_{X}^{C} \cdot P Q_{X, t}^{1-\sigma_{W}^{n e s t}}+\left(1-\theta_{X}^{C}\right) \cdot P Q_{Y, t}^{1-\sigma_{W}^{n e s t}}\right]^{\frac{1}{1-\sigma_{W}^{n}}}$

$\perp W_{t}$ $t=1, . ., T$

(A.8)

$$
\prod_{t=1}^{T} P W_{t}^{\frac{\theta^{W}}{T \cdot \theta^{W}}}=P U
$$

\section{Unit demand functions}

$$
D_{i, t}^{R K Q}=\alpha_{i}^{Q} \cdot \frac{P Q_{i, t}}{R K_{t}}
$$$$
i=X, Y ; t=1, . ., T
$$

$$
D_{i, t}^{L Q}=\beta_{i}^{Q} \cdot \frac{P Q_{i, t}}{P L_{t}}
$$$$
i=X, Y ; t=1, . ., T
$$

$$
D_{i, t}^{E Q}=\chi_{i} \cdot \frac{P Q_{i, t}}{P E_{t}}
$$$$
i=X, Y ; t=1, . ., T
$$

$$
D_{i, t}^{P K C Q}=\left(1-\alpha_{i}^{Q}-\beta_{i}^{Q}-\chi_{i}\right) \cdot \frac{P Q_{i, t}}{P K C_{i, t}}
$$$$
i=X, Y ; t=1, . ., T
$$

$$
D_{i, t}^{R K Z}=\alpha_{i}^{Z} \cdot \frac{P Z_{i, t}}{R K_{t}}
$$$$
i=X, Y ; t=1, . ., T
$$$$
i=X, Y ; t=1, . ., T
$$

$$
D_{X, t}^{W}=\left(\theta_{C}^{W} \cdot \frac{P W_{t}}{P C_{t}}\right)^{\sigma_{W}} \cdot\left(\theta_{X}^{C} \cdot \frac{P C_{t}}{P Q_{X, t}}\right)^{\sigma_{W}^{\text {nest }}}
$$

$$
D_{Y, t}^{W}=\left(\theta_{C}^{W} \cdot \frac{P W_{t}}{P C_{t}}\right)^{\sigma_{W}} \cdot\left(\left(1-\theta_{X}^{C}\right) \cdot \frac{P C_{t}}{P Q_{Y, t}}\right)^{\sigma_{W}^{\text {nest }}}
$$

$$
t=1, . ., T
$$

$$
t=1, . ., T
$$

$$
D_{t}^{L W}=\left(\left(1-\theta_{C}^{W}\right) \cdot \frac{P W_{t}}{P L_{t}}\right)^{\sigma_{W}}
$$

$$
t=1, . ., T
$$




$$
D_{t}^{W U}=\frac{\theta_{t}^{W}}{\sum_{t=1}^{T} \theta_{t}^{W}} \cdot \frac{P U}{P W_{t}}
$$

Coefficients

$$
r_{i}^{P K C}=\frac{\sigma_{i}^{N}}{\sigma_{i}^{N}-1}
$$$$
i=X, Y
$$

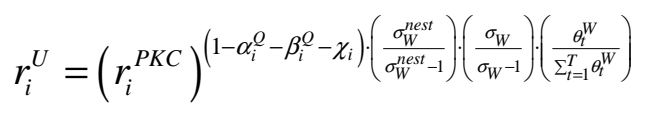$$
i=X, Y
$$

$$
\bar{L}_{t}=(1+g)^{t-1} \cdot \bar{L}_{0}
$$$$
t=1, . ., T
$$

$$
\bar{E}_{t}=(1+g)^{t-1} \cdot \bar{E}_{0}
$$$$
t=1, . ., T
$$

\section{Market clearance conditions}

$$
\begin{aligned}
& Q_{i, t}=C_{i, t}+\theta_{i}^{I} \cdot I_{t}+N_{i, t} \\
& \text { with } C_{i, t}=D_{i, t}^{W} \cdot W_{t}
\end{aligned}
$$

$\perp P Q_{i, t} \quad i=X, Y ; t=1, . ., T$

(A.28)

$$
\left(N S_{i, t} \cdot P Z_{i, t}^{1-\sigma_{i}^{N}}\right)^{\frac{1}{1-\sigma_{i}^{N}}}=P K C_{i, t}
$$

$\perp P K C_{i, t} \quad i=X, Y ; t=1, . ., T$

$$
Z_{i, t}=D_{i, t}^{P K C Q} \cdot N S_{i, t}{ }^{\frac{1}{1-\sigma_{i}^{N}}} \cdot Q_{i, t}
$$$$
\perp P Z_{i, t} \quad i=X, Y ; t=1, . ., T
$$

$$
N S_{i, t=1}=\overline{N S}_{i, 0}
$$

$$
N S_{i, t}=\left(1-\delta_{i}^{N}\right) \cdot N S_{i, t-1}+N_{i, t-1}
$$

$\perp P N_{i, t=1}$

$$
i=X, Y
$$

$$
N S_{i, T} \cdot\left(1-\delta_{i}^{N}\right)+N_{i, T}=T N_{i}
$$

$\perp P N_{i, t} \quad i=X, Y ; t=2, . ., T$

$$
Z_{i, t} \cdot \frac{1}{\sigma_{i}^{N}-1}=F C_{i}
$$

$\perp P N T_{i}$

$$
i=X, Y
$$

$\perp P F C_{i, t} \quad i=X, Y ; t=1, . ., T$

$\perp P K_{t=1}$

$$
\begin{gathered}
K_{t}=\left(1-\delta^{K}\right) \cdot K_{t-1}+I_{t-1} \\
K_{T} \cdot\left(1-\delta^{K}\right)+I_{T}=T K
\end{gathered}
$$

$\perp P K_{t}$

$\perp P K T$

(A.29)

$$
\begin{array}{cll}
\frac{K_{t} \cdot R K_{t}}{i r+\delta^{K}}=\sum_{i=X, Y}\left(D_{i, t}^{R K Q} \cdot Q_{i, t}+D_{i, t}^{R K Z} \cdot N S_{i, t} \cdot Z_{i, t}\right) & \perp R K_{t} & t=1, . ., T \\
\bar{L}_{t}=\sum_{i=X, Y}\left(D_{i, t}^{L Q} \cdot Q_{i, t}+D_{i, t}^{L Z} \cdot N S_{i, t} \cdot Z_{i, t}\right) & & \\
+D_{t}^{L W} \cdot W_{t} & \perp P L_{t} & t=1, . ., T \\
e r_{t} \cdot \overline{E_{t}}=\sum_{i=X, Y} D_{i, t}^{E Q} \cdot Q_{i, t} & \perp P E_{t} & t=1, . ., T \\
W_{t}=D_{t}^{W U} \cdot U & \perp P W_{t} & t=1, . ., T
\end{array}
$$




$$
U=\prod_{i=X, Y} r_{i}^{U} \cdot \frac{M}{P U} \quad \perp P U
$$

Income balance

$$
M=\sum_{t=1}^{T}\left(P L_{t} \cdot \bar{L}_{0} \cdot g_{t}^{R E F}+P E_{t} \cdot \bar{E}_{0} \cdot g_{t}^{R E F} \cdot e r_{t}\right)+P K_{t=1} \cdot \bar{K}_{0}-T K \cdot P K T
$$

Terminal constraints

$$
\begin{gathered}
\frac{I_{T}}{I_{T-1}}=\frac{W_{T}}{W_{T-1}} \\
\frac{N_{i, T}}{N_{i, T-1}}=\frac{W_{T}}{W_{T-1}}
\end{gathered}
$$

\section{Nomenclature}

Sets and indices

$\begin{array}{ccl}i & X, Y & \text { Sectors and goods } \\ t & 1, . ., T & \text { Time periods }\end{array}$

Activity variables

$Q_{i, t}$ Aggregate production of goods

$Z_{i, t}$

Production of an individual variety of knowledge capital

$N S_{i, t}$

Stock of blueprints / varieties of knowledge capital

$T N_{i}$

Terminal stock of blueprints / varieties of knowledge capital

$N_{i, t}$

Investments in blueprints (R\&D)

$K_{t}$

Stock of physical capital

$T K$

Terminal stock of physical capital

$I_{t}$

Investments in physical capital

$C_{i, t}$

Aggregate consumption

$W_{t}$

Instantaneous utility

$U$

Intertemporal utility 
Price variables (in present values)

$\begin{array}{ll}P Q_{i, t} & \text { Price of goods } \\ P C_{t} & \text { Composite price of goods } \\ P K C_{i, t} & \text { Unit cost of knowledge capital } \\ P Z_{i, t} & \text { Price of an individual variety of knowledge capital } \\ P N_{i, t} & \text { Price of a blueprint } \\ P N T_{i} & \text { Price of terminal stock of blueprints } \\ P F C_{i, t} & \text { Unit price of inputs to the R\&D related set-up costs } \\ P K_{t} & \text { Price of physical capital } \\ P K T & \text { Price of terminal stock of physical capital } \\ R K_{t} & \text { Rental rate for physical capital } \\ P L_{t} & \text { Wage rate } \\ P E_{t} & \text { Price of emission permits } \\ P W_{t} & \text { Price of instantaneous utility } \\ P U & \text { Price of intertemporal utility }\end{array}$

Income- and endowment variables

$M$

Total income of the representative agent

$\overline{N S}_{i, 0}$

Initial stock of blueprints / varieties of knowledge capital

$\bar{K}_{0}$

Initial stock of physical capital

$\bar{L}_{t}$

Endowment of labor

$\bar{E}_{t}$

Endowment of emission rights

Unit demand variables

$D_{i, t}^{P K C Q} \quad$ Unit demand for knowledge capital in the production of goods

$D_{i, t}^{R K Q} \quad$ Unit demand for physical capital in the production of goods

$D_{i, t}^{L Q} \quad$ Unit demand for labor in the production of goods

$D_{i, t}^{E Q} \quad$ Unit demand for emission rights in the production of goods

$D_{i, t}^{R K Z} \quad$ Unit demand for physical capital in the production of knowledge capital

$D_{i, t}^{L Z} \quad$ Unit demand for labor in the production of knowledge capital 
$D_{i, t}^{W} \quad$ Unit demand for goods in instantaneous utility

$D_{t}^{L W} \quad$ Unit demand for leisure in instantaneous utility

$D_{t}^{W U} \quad$ Unit demand for instantaneous utility in the intertemporal utility function

\section{Coefficients}

er $\quad$ Emission rights index

ir Interest rate

$F C_{i} \quad$ Set-up costs related to R\&D

$g \quad$ Growth rate

$\delta^{K}, \delta_{i}^{N} \quad$ Depreciation rates

$r_{i}^{P K C} \quad$ Degree of homogeneity in the aggregate production of knowledge capital

$r_{i}^{U} \quad$ Degree of homogeneity in intertemporal utility

$\theta_{i}^{I}, \theta_{X}^{C}, \theta_{C}^{W}, \theta_{t}^{W} \quad$ Share coefficients

$\alpha_{i}^{Q}, \alpha_{i}^{Z}, \beta_{i}^{Q}, \beta_{i}^{Z}, \chi_{i}$ Cost price coefficients

$\gamma_{i} \quad$ Knowledge spillover coefficient

$\phi_{i}, v_{i}, \xi_{i} \quad$ Feedback effects

$\sigma_{i}^{N}, \sigma_{W}, \sigma_{W}^{\text {nest }} \quad$ Substitution elasticities 


\section{References}

Acemoglu, D., 2002, Directed technical change, Review of Economic Studies 69 (4), 781 809.

Aghion, P. and P. Howitt, 1992, A model of growth through creative destruction, Econometrica 60 (2), 323-351.

Basu, S. and D.N. Weil, 1998, Appropriate technology and growth, Quarterly Journal of Economics 113 (4), 1025-1054.

Buonanno, P., Carraro, C. and M. Galeotti, 2003, Endogenous induced technical change and the costs of Kyoto, Resource and Energy Economics 25 (1), 11-34.

Ferris, M.C. and T.S. Munson, 2000, Complementarity problems in GAMS and the PATH solver, Journal of Economic Dynamics and Control 24 (2), 165-188.

Gerlagh, R. and W. Lise, 2003, Induced technological change under carbon taxes, Working Paper No. 84.2003, FEEM.

Gerlagh, R. and B.v.d. Zwaan, 2003, Gross world product and consumption in a global warming model with endogenous technological change, Resource and Energy Economics 25 (1), 35-57.

Goulder, L.H. and K. Mathai, 2000, Optimal CO2 abatement in the presence of induced technological change, Journal of Environmental Economics and Management 39, 138.

Goulder, L.H. and S.H. Schneider, 1999, Induced technological change and the attractiveness of CO2 abatement policies, Resource and Energy Economics 21, 211-253.

Jakeman, G., Hanslow, K., Hinchy, M., Fisher, B.S. and K. Woffenden, 2004, Induced innovations and climate change policy, Energy Economics 26, 937-960.

Lau, M.I., Pahlke, A. and T.F. Rutherford, 2002, Approximating infinite-horizon models in a complementarity format: A primer in dynamic general equilibrium analysis, Journal of Economic Dynamics and Control 26, 577-609.

Nordhaus, W.D., 1999, Modeling induced innovation in climate change policy, paper for workshop "Induced Technological Change and the Environment" June 21-22, IIASA.

Popp, D., 2003, ENTICE: Endogenous technological change in the DICE model of global warming, Working paper 9762, NBER.

Rivera-Batiz, L.A. and P.M. Romer, 1991, Economic integration and endogenous growth, Quarterly Journal of Economics 106 (2), 531-555.

Romer, P.M., 1990, Endogenous technological change, Journal of Political Economy 98 (5), 71-102.

Rutherford, T.F., 1999, Applied general equilibrium modeling with MPSGE as a GAMS subsystem: An overview of the modeling framework and syntax, Computational Economics 14, 1-46.

Sue Wing, I., 2003, Induced technical change and the cost of climate policy, Report No. 102, MIT Joint Program on the Science \& Policy of Global Change. 